\section{Effect of Post Metallization Annealing for Alternative Gate Stack Devices}

I. Kim, S.K. Han and C.M. Osburn

North Carolina State University, Raleigh, NC 27695

To meet the gate leakage specifications in the International Technology Roadmap for Semiconductors (ITRS), an intensive search is being conducted for alternative gate stack materials. Most of the studies have focused on basic material properties, but very little effort has been directed towards quantifying and understanding the effect of post metallization annealing (PMA) on the electrical properties of the dielectric. In this work, devices were fabricated with a "gate last" process. The gate dielectrics studied included: $\mathrm{HfO}_{2}$ deposited by PVD or MOCVD, as well as $\mathrm{Y}_{2} \mathrm{O}_{3}$ and $\mathrm{La}_{2} \mathrm{O}_{3}$ deposited by RPECVD and MBE, respectively. Poly-Si gate electrodes were prepared by $600^{\circ} \mathrm{C}$ LPCVD followed by ion implantation and dopant activation using $900^{\circ} \mathrm{C} 60 \mathrm{sec}$ RTA. Device characteristics were measured before and after 20 min $400-450^{\circ} \mathrm{C}$ forming gas $\left(\mathrm{FG}, 10 \% \mathrm{H}_{2}\right.$ in $\mathrm{N}_{2}$ ) annealing. To verify the role of hydrogen in PMA, some devices were annealed in nitrogen only. Capacitance versus voltage $(\mathrm{CV})$, gate leakage current, drain current versus gate voltage, and drain current versus drain voltage were measured. MOSFET device parameter analysis programs with corrections for quantum mechanical effects $[1,2]$ were used to extract key device parameters: equivalent oxide thickness (EOT), metal-tosemiconductor workfunction, substrate doping, channel mobility as a function of electric field, number of interface scattering charges $\left(\mathrm{N}_{\mathrm{if}}\right)$, and the interface roughness scattering parameters $(\mathrm{L} * \mathrm{H}$ product)

PVD $\mathrm{HfO}_{2}(1.2 \mathrm{~nm}$ EOT) with Poly $\mathrm{Si}$ gates exhibited only a minor change in $\mathrm{CV}$ and gate leakage current after the $400^{\circ} \mathrm{C}$ FG PMA. Likewise, the device threshold voltage shift was negligible. But as shown in Figs. 1 and 2, there was a dramatic enhancement in the device current and about $46 \%$ higher mobility, which was interpreted in terms of reduced charge $\left(8 \mathrm{e} 10^{10} / \mathrm{cm}^{2}\right.$ after PMA versus $1.2 \mathrm{e} 10^{11} / \mathrm{cm}^{2}$ before) and roughness scattering $\left(39 \AA^{2}\right.$ after vs. $65 \AA^{2}$ before). As a reference point, high quality oxide might typically have $3 \mathrm{e} 10^{10} / \mathrm{cm}^{2}$ interface charges and $25 \AA^{2}$ of roughness scattering; thus PMA of this $\mathrm{HfO}_{2}$ was not sufficient to give as high a mobility as $\mathrm{SiO}_{2}$. Nevertheless, the forming gas anneal in this case does seem to eliminate interface states between $\mathrm{HfO}_{2}$ and the substrate, resulting in higher current and mobility.

For the group III materials with poly-Si gates (MBE $\mathrm{La}_{2} \mathrm{O}_{3}$ and MOCVD $\mathrm{Y}_{2} \mathrm{O}_{3}$ ), post metallization annealing also resulted in higher device current. For $\mathrm{La}_{2} \mathrm{O}_{3}$, PMA shifted both the flatband and the threshold voltages by the same amount $(300 \mathrm{mV})$ indicative of a reduction in fixed oxide charge. On the other hand, $\mathrm{Y}_{2} \mathrm{O}_{3}$ showed a $200 \mathrm{mV}$ shift only in the threshold voltage- - not in the flatband voltage. The EOT values from CV data resulted in anomalously high values of mobility. Here the mobility parameters, including EOT, were extracted from device I-V data based on the assumptions that: a) EOT was not affected by PMA and b) the post-PMA scattering parameters were the same as good $\mathrm{SiO}_{2}\left(3 \mathrm{e} 10 / \mathrm{cm}^{2}\right)$. Peak mobility of $63 \%$ and $57 \%$ higher were observed for $\mathrm{La}_{2} \mathrm{O}_{3}$ and $\mathrm{Y}_{2} \mathrm{O}_{3}$, respectively. Dramatic reductions in interface scattering charges were observed: from 19 and 11 e10/cm ${ }^{2}$ for $\mathrm{Y}_{2} \mathrm{O}_{3}$ and $\mathrm{La}_{2} \mathrm{O}_{3}$ respectively, to $3 \mathrm{e} 10 / \mathrm{cm}^{2}$. The roughness scattering parameters did not change much It seems that the FG post metallization annealing reduces interface charge also for group III materials. The gate leakage was not affected by PMA for either material.

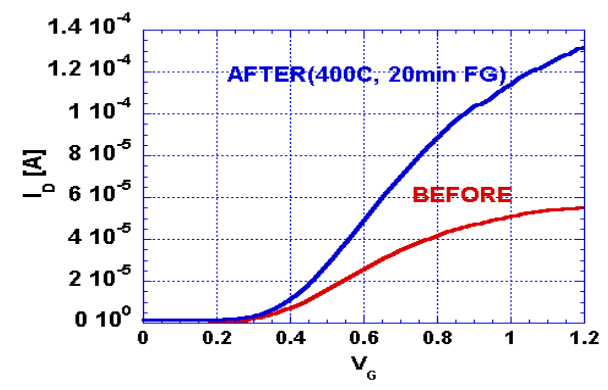

Fig. 1. $\mathrm{I}_{\mathrm{d}}-\mathrm{V}_{\mathrm{d}}$ characteristic of $\mathrm{PVD} \mathrm{HfO}_{2}$ and Poly-Si devices before and after PMA. $\left(\mathrm{V}_{\mathrm{dd}}=50 \mathrm{mV}\right)$

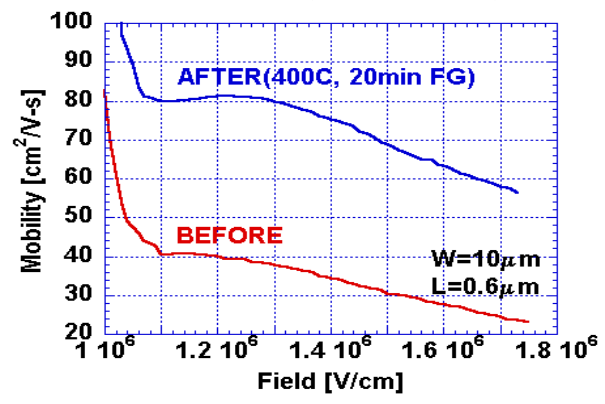

Fig. 2. Mobility of PVD $\mathrm{HfO}_{2}$ and Poly-Si devices before and after PMA

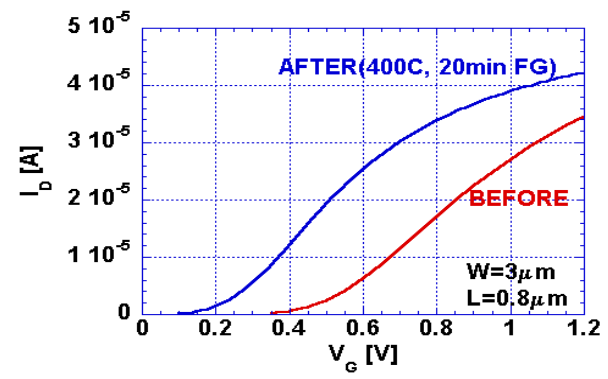

Fig. 3. $\mathrm{I}_{\mathrm{d}}-\mathrm{V}_{\mathrm{d}}$ characteristic of MOCVD $\mathrm{Y}_{2} \mathrm{O}_{3}$ and Poly-Si devices before and after PMA $\left(\mathrm{V}_{\mathrm{dd}}=50 \mathrm{mV}\right)$

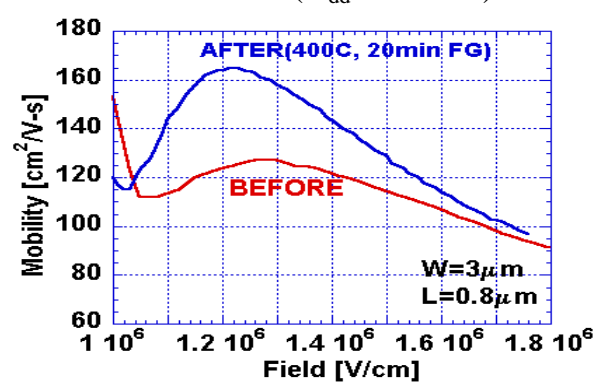

Fig. 4. Mobility of MOCVD $\mathrm{Y}_{2} \mathrm{O}_{3}$ and Poly-Si devices before and after PMA

Acknowledgements

The dielectrics and gate electrodes used in this work were deposited by research group of J. Lee at UT-Austin and A. Kingon and G. Parsons at NCSU. The authors would like to acknowledge the support of SRC and SEMATECH in this work.

\section{References}

1. J. Hauser and K. Ahmed, "Characterization of ultrathin oxides using electrical C-V and I-V measurements," AIP Conference Proceedings, p.235, Gaithersburg, MD, Mar. 23-27(1998)

2. J.R. Hauser, "Extraction of Experimental Mobility Data for MOS Devices," IEEE Trans. ED, 43, 1981(1996) 